\title{
Melamine detection using a paper microfluidic device
}

\author{
Wu RG ${ }^{1}$, Zhong $Z W^{2 *}$, Ankit ${ }^{2}$, Chee $\mathrm{JY}^{2}$, Wang $\mathrm{C}^{2}$ and Fun $\mathrm{KF}^{2}$ \\ ${ }^{1}$ Singapore Institute of Manufacturing Technology, 71 Nanyang Drive, Singapore 638075, Singapore \\ ${ }^{2}$ School of Mechanical and Aerospace Engineering, Nanyang Technological University, 50 Nanyang Avenue, Singapore 639798, Singapore
}

\begin{abstract}
A study of the paper-based microfluidic devices was carried out for melamine detection. Paper-based microfluidic detection was chosen for the experiments, as it could be the most cost effective, compared to other detection techniques, which would require expensive instruments. Experimental results revealed a very good depletion of bovine serum albumin from the target analyte (melamine). UV-vis absorbance value curves of the mixture solution and extraction solution showed the extraction of the small molecule (melamine) by the developed paper microfluidic device. It is concluded that the H-filter can be used for determination of adulterated melamine in dairy products.
\end{abstract}

\section{Introduction}

Toxic ingredients might be found in food, together with the essential elements [1]. High melamine exposure might enhance the risks of kidney injury and kidney stone formation in infants [2]. Melamine had been added into cattle feed as a non-protein nitrogen from 1958 to 1978. This was discontinued because the melamine was found hydrolyzed completely in ruminants and not performing as a satisfactory nitrogen source [3]. The conventional way to measure the protein level was to test the content of nitrogen by Kjeldahl and Dumas testing [4], and the nitrogen content of melamine is about $66 \%$ by mass [5]. That was why some immoral producers added melamine into dairy products, animal feeds and other foods to improve the content of protein on the data to meet the national standard and attract customers to buy their products [6]. The adulteration of protein-based food products with melamine is now a well- known issue, and in the case of 2008 milk adulteration scandal, melamine was added to the milk to give consistent protein readings and increase the profits dishonestly [7]. Melamine is added to increase the nitrogen content, giving a false reading on the apparent protein level [8]. In fact, melamine is a synthetic chemical compound primarily used in the manufacture of laminates, plastics, coatings, commercial filters, adhesives and dishware/kitchenware. Miscreants adulterate milk and agricultural food products with melamine $[9,10]$. The main concern on melamine, as a food additive, is the ability of combining with its analogues, such as cyanuric acid, leading to the formation of insoluble crystals, which are responsible for kidney failures and even death in infants [11]. WHO and FDA, US had established the daily intake limits for melamine by adults and children as 2.5 and $2.0 \mathrm{mg}$ per kg of body weight respectively [12]. The safety limit for melamine in the United States was around 2.5 ppm and was the same in European Union, and the safety limit was 1 ppm in China for infant formula [13].

The detection of adulteration of milk with melamine is not possible by conventional methods, because these methods are unable to differentiate between proteic and non-proteic nitrogens [14]. The assured determination of melamine in agricultural and food products demands the combination of a separation technique and a detection tool [15]. Commonly used approaches involve liquid chromatography, photodiode array detector or ultraviolet (UV) detection.
Although these methods can achieve a limit of detection (LOD) and limit of quantification (LOQ) as low as $0.3 \mathrm{ppb}$, they often require labour intensive and time consuming sample pre- treatment, which interferes with high-throughput detection necessary for use in food industry [15]. The microfluidic electrophoresis device (MED) is also one of the tools for analytical detection of melamine in adulterated milk using the UV detection technique without the need of pre-treatment [16].

After the scandal of melamine tainted infant milk in 2008, simple, fast and cost-effective techniques to test the protein in milk products have to be developed [17], to discourage adulteration from bad milk manufacturers. New test methods include high performance liquid chromatography [18], gas chromatography/mass spectrometry [17], Raman spectroscopy $[19,20]$ and enzyme-linked immunosorbent assay [21]. However, these techniques demand costly instruments and personnel, and are labor-intensive and time-consuming [22]. The modern instrument analytical methods to detect melamine include nuclear magnetic resonance [23], matrix assisted laser desorption/ ionization-mass spectrophotometry [24], capillary electrophoresis [25], near-infrared spectroscopy [26], Fourier transform infrared spectra [27- 29], mid-infrared analysis [30], high-field H-1 NMR spectroscopy [31] etc. Those methods are very sensitive, but expensive instrumentation and high labor costs may be required.

One simple, fast and cost-effective method for melamine assay is using paper-based microfluidic devices. The first paper-based microfluidic technology was proposed to measure glucose in urine [8]. Since the first introduction of paper-based dipsticks, lateral flow devices have expanded to clinical tests, food diagnostics, environmental applications and drug abuse diagnostics [4]. Because of new readout

${ }^{*}$ Correspondence to: Zhong ZW, School of Mechanical and Aerospace Engineering, Nanyang Technological University, 50 Nanyang Avenue, Singapore 639798, Singapore

Key words: detection, melamine, paper-based microfluidic device, H-filter, bovine serum albumin, milk

Received: October 14, 2020; Accepted: October 22, 2020; Published: October 26,2020 
approaches, functional coatings and the advances of paper-based devices, paper-based assays and sensors emerged expeditiously [32]. Paper-based microfluidic devices are easy to fabrication, user-friendly, etc [33]. Paper-based analytical devices can be disposable for cheap, in-situ and on-hand detection applications $[34,35]$. The devices may be applied not only in the detection of melamine but also in the separation and extraction of melamine in the protein. They may separate and extract the relatively small molecular substance from the mixture.

Separation of two different molecules and consequent distillation of the faster diffusing species can be accomplished by introducing a mixture solution at one inlet and the buffer solution at the other inlet. The performance of the distillation process relies upon the diffusion coefficient of each species, the contact time, and the dimensions of the common channel. No intervening membrane is needed as long as the Reynolds number in the device is low, an inherent property of paper based microfluidic devices. The utility of a conventional microfluidic device used as an $\mathrm{H}$ filter has been limited, because of the requirement for precise pumps and longtime taken to establish stable fluid flow. The two-dimensional paper $\mathrm{H}$-filter promises as an autonomous solution for the extraction of small molecules from a mixture of big and small molecules, and acts as an anchor for more applications for complex paper microfluidic devices [36-39].

The convective mixing of fluid does not occur in microfluidic channels, owing to the fact that Reynolds number is maintained well below 1. Diffusion is responsible for the movement of solvents, solutes and suspended particles in the cross-direction to the direction of flow [40]. The root mean square distance traversed by a molecule in a time interval, $t$, is given by the Einstein relation for molecular diffusion in solution [40],

$$
X r m s=(2 D t)^{1 / 2}
$$

where $D$ is the molecular diffusion coefficient. The diffusion coefficient is known to increase in some relation with the inverse of the size of the molecule and is also dependent to some degree on the shape of the molecule. Hence, small molecules have large diffusion coefficients and will move a longer average distance per unit time than large molecules. This difference in diffusion coefficients of small and large molecules forms the basis for $\mathrm{H}$-filters and can be employed to separate molecules over duration. In the $\mathrm{H}$-filter, the time used up flowing in a stream is proportionate to the length of the channel, and thus the proper design of the channel allows regulated extraction of smaller molecules from a mixture solution containing small and big molecules [40].

In our previous work, microfluidic devices were used to separate and extract the tartrazine from the mixture solution of tartrazine and blue black bovine serum. The experiment got high purity tartrazine [41]. The experiment of our previous research gives us the idea that we may find the way to purify the protein that is contaminated by melamine, using a paper-based microfluidic device.

This work aimed to test cost-effective paper-based microfluidics combining separation and detection of melamine on a single piece of filter paper. Previous works did not incorporate both techniques in a single step for separation and detection. The objective is to separate and isolate melamine from milk compounds on paper-based microfluidics to detect melamine in a single step procedure. Also, compared to other techniques, a paper-based microfluidic device may be a better choice, as it is considerably the most cost effective at the current point of time. As paper is also used around the world, poorer nations such as third world countries could utilise paper to make point-of-care diagnostics.
The concept that we are trying to investigate here has not been done before. It has not been tried to use the $\mathrm{H}$-filter for separation and analytical detection of melamine in adulterated milk samples. The H-filter design, which is used for the extraction and separation analysis, has been used for experiments. The concept of extraction of small molecules from a mixture of big and small molecules using an $\mathrm{H}$-filter can be applied, as melamine is a very small molecule compared to other fats and proteins present in the milk sample. This method would isolate melamine from other interfering materials in the milk sample for accurate analysis by various detection techniques.

\section{Materials and methods}

\section{Extraction and absorbance plot}

Figure 1 shows the experiment of the separation in the H-filter in process. We can observe an interface between the mixture solution and buffer solution in the central channel of the $\mathrm{H}$ - filter. The apparatus allowed to run the micro-fluid till it reached the end of the paper device. After this, the left and right portions of the extraction region were cut and put in a microfuge tube. $\mathrm{DI}_{2} \mathrm{O}$ of $50 \mu \mathrm{L}$ was added in the microfuge tube and vortex.

The regions were analysed using a Nanodrop Spectrophotometer doing the UV-Vis analysis. The mixture contained Tartrazine and Blue-BSA, in which Tartrazine was the small molecule and BSA was the big molecule. The UV-Vis analysis was conducted for 2 known wavelengths, $590 \mathrm{~nm}$ for BSA and $422 \mathrm{~nm}$ for Tartrazine. The left side of the extraction region gave the small molecules by the concept of $\mathrm{H}$-filters, and the right side contained the mixture of big and small molecules, as the inlet of the buffer solution to the paper device was from the left arm of the H-filter. $2 \mathrm{H}$-filter dimensions were used for the experiments, with the lengths of $2 \mathrm{H}$-filters being $20 \mathrm{~mm}$ and 25 $\mathrm{mm}$ and other dimensions remaining the same. The UV-Vis plot was obtained for the left hand side (LHS) and the right hand side (RHS) of the extraction region.

\section{Standard curve for tartrazine}

To analyse the concentration of tartrazine separated out by $\mathrm{H}$-filter separation from the mixture solution, the absorption curves for various known concentrations of Tartazine were obtained with the UV-Vis Spectroscopy. Four tartrazine solutions were prepared in DI H2O with known concentrations of $0.2,0.3,0.4$ and $0.5 \mathrm{mg} / \mathrm{ml}$.

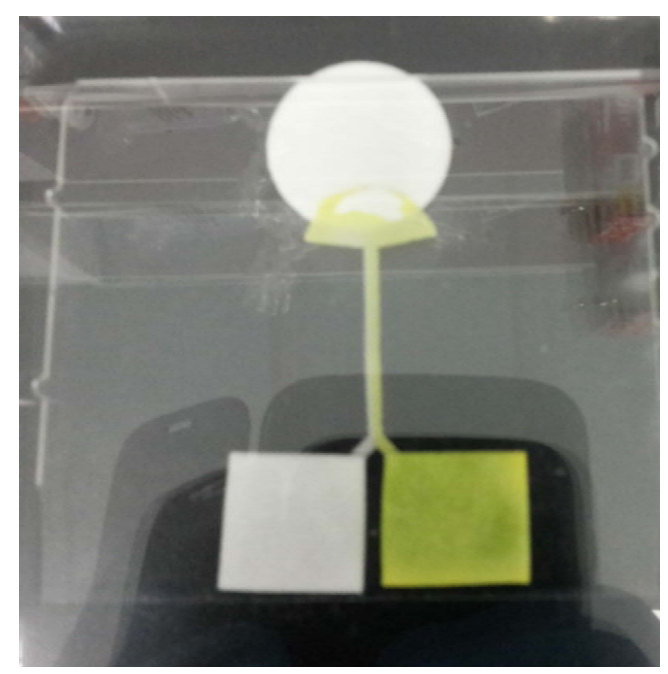

Figure 1. Observation of the separation in the H-filter 


\section{Calculation of extraction amount of tartrazine}

The absorbance values of tartrazine in the left extraction region were used and substituted in the equation for calculating the concentrations in the left region. As after cutting the extraction regions they were put in the microfuge tube and diluted with $50 \mu \mathrm{L}$ of DI H2O, the volume of the solution could be taken as $0.05 \mathrm{ml}$. Therefore, the amount of tartrazine extracted could be calculated by multiplying the concentration and volume.

As the mixture solution contained the known concentration of $0.5 \mathrm{mg} / \mathrm{ml}$ of tartrazine and the volume of mixture solution loaded for the $\mathrm{H}$-filter separation was $0.2 \mathrm{ml}$, the amount of tartrazine loaded was calculated. The percentage of extraction was calculated using the concentration extracted divided by concentration loaded.

\section{Separation of milk-melamine}

Milk-melamine solution was prepared by adding $200 \mu \mathrm{L}$ of full cream milk or Bovine serum albumin (BSA) solution and $200 \mu \mathrm{L}$ of $200 \mathrm{mg} / \mathrm{L}$ melamine solution in $1 \times$ PBS solution. $50 \mu \mathrm{L}$ mixture was applied to an $\mathrm{H}$-filter chip for separation. 4 samples were collected from soaking of different segments of the $\mathrm{H}$-filter in $50 \mu \mathrm{L} 1 \mathrm{xPBS}$, as shown in Figure 2. The 4 samples were tested by Nanodrop testing. Sample 1 was the rightest most of the chip and sample 4 was from the left end of the chip.

\section{Results and discussion}

\section{Results of extraction and absorbance plot}

The plot in Figure 3 shows the absorbance on the vertical axis against the wavelength on the horizontal axis. The peak values at 422 $\mathrm{nm}$ were obtained for tartrazine and at $590 \mathrm{~nm}$ for Blue-BSA.

For the H-filters of length 20 and $25 \mathrm{~mm}$, Table 1 lists the absorbance values at 422 and $590 \mathrm{~nm}$ for both left and right sample extraction regions. The same experiment was carried out 3 times for each dimension of $20 \mathrm{~mm}$ and $25 \mathrm{~mm}$ respectively of the $\mathrm{H}$-filter devices.

These absorbance values have been used for calculating the amount of tartrazine extracted from the mixture solution after the H-filter separation. For calculating the amount of tartrazine, we also need to plot the standard curve for the tartrazine.

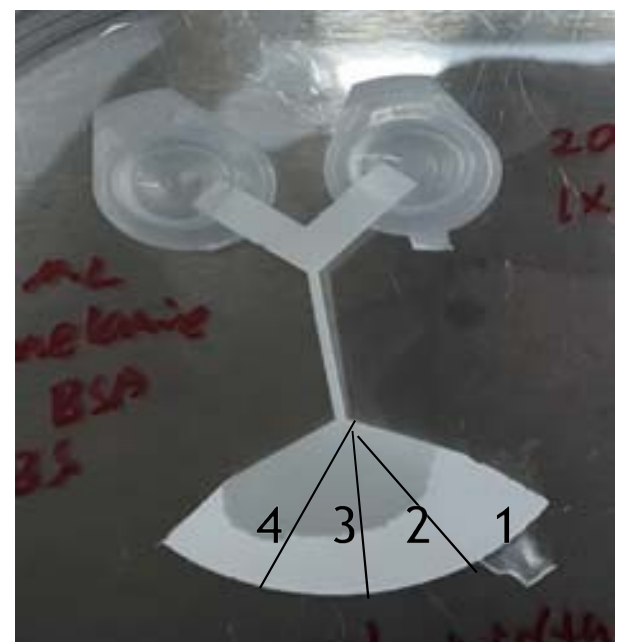

Figure 2. The four segments cut from the $\mathrm{H}$ filter for soaking after separation of melamine from milk sample
Table 1. Absorbance Values for the H-filters of length 20 and $25 \mathrm{~mm}$

\begin{tabular}{|c|c|c|c|c|c|c|}
\hline & & Sample ID & $1(\mathrm{~nm})$ & 1 (ABS) & $2(\mathrm{~nm})$ & 2 (ABS) \\
\hline \multirow{6}{*}{$\begin{array}{l}\text { Length of H-filter } \\
=20 \mathrm{~mm}\end{array}$} & \multirow[t]{2}{*}{ Experiment 1} & $\begin{array}{l}\text { Left (Purified } \\
\text { Tartrazine) }\end{array}$ & 422 & 0.202 & 590 & 0 \\
\hline & & Right (Mixture) & 422 & 0.104 & 590 & 0.002 \\
\hline & \multirow{2}{*}{ Experiment 3} & $\begin{array}{l}\text { Left (Purified } \\
\text { Tartrazine) }\end{array}$ & 422 & 0.204 & 590 & 0 \\
\hline & & Right (Mixture) & 422 & 0.107 & 590 & 0.005 \\
\hline & \multirow[t]{2}{*}{ Experiment 5} & $\begin{array}{l}\text { Left (Purified } \\
\text { Tartrazine) }\end{array}$ & 422 & 0.202 & 590 & 0 \\
\hline & & Right (Mixture) & 422 & 0.111 & 590 & 0.003 \\
\hline \multirow{7}{*}{$\begin{array}{l}\text { Length of } \mathrm{H} \text { - } \\
\text { filter }=25 \mathrm{~mm}\end{array}$} & \multirow[t]{2}{*}{ Experiment 2} & $\begin{array}{l}\text { Left (Purified } \\
\text { Tartrazine) }\end{array}$ & 422 & 0.196 & 590 & 0 \\
\hline & & Right (Mixture) & 422 & 0.095 & 590 & 0.001 \\
\hline & \multirow[t]{2}{*}{ Experiment 4} & $\begin{array}{l}\text { Left (Purified } \\
\text { Tartrazine) }\end{array}$ & 422 & 0.189 & 590 & 0 \\
\hline & & Right (Mixture) & 422 & 0.104 & 590 & 0.002 \\
\hline & \multirow{3}{*}{ Experiment 6} & Left (Purified & \multirow{2}{*}{422} & \multirow{2}{*}{0.198} & \multirow{2}{*}{590} & \multirow[b]{2}{*}{0} \\
\hline & & Tartrazine) & & & & \\
\hline & & Right (Mixture) & 422 & 0.101 & 590 & 0.005 \\
\hline
\end{tabular}

Table 2. Absorbance values for known concentrations of tartrazine

\begin{tabular}{|c|c|c|}
\hline & Concentration $\mathbf{( m g / m l )}$ & Abs (at 422 $\mathbf{~ n m})$ \\
\hline Tartrazine Solution 2 & 0.2 & 1.119 \\
\hline Tartrazine Solution 1 & 0.3 & 1.421 \\
\hline Tartrazine Solution 3 & 0.4 & 1.748 \\
\hline Tartrazine Solution 4 & 0.5 & 2.207 \\
\hline
\end{tabular}

\section{Results of the standard curve for tartrazine}

Figure 4 shows the absorbance values plotted along the vertical axis and the wavelengths along the horizontal axis. We can see that the peaks of the curves are at around $422 \mathrm{~nm}$. The peak values at 422 $\mathrm{nm}$ were measured for these tartrazine solutions, and they are listed in Table 2.

As seen in Figure 5, along the vertical axis the absorbance values are plotted, and along the horizontal axis the concentration values are plotted. The equation for line of best fit passing through origin is obtained as $y=4.5422 x$. This equation provides the base for calculating unknown concentrations from the absorbance values.

\section{Results of the calculation for extraction amount of tartrazine}

The absorbance values of tartrazine in the left extraction region from Table 1 were used and substituted in the equation for calculating the concentrations in the left region. The calculation results are shown in Table 3. The concentrations of tartrazine extracted using the 20 and $25 \mathrm{~mm}$ H-filters come as 0.0445 and $0.0431 \mathrm{mg} / \mathrm{ml}$, respectively.

The percentage of extraction was calculated using the concentration extracted divided by concentration loaded, and is shown in Table 4. From the table, around 2 percent extraction of purified Tartrazine was observed from the loaded sample for the two designs (20 and $25 \mathrm{~mm}$ lengths) of the paper device. The extraction percentages appear to be consistent with the design of the $\mathrm{H}$-filter, and this result can be used to reverse-calculate the percentage of small molecules in the mixture itself.

The experimental results showed that " $\mathrm{H}$ filters can be used for extraction and separation of small molecules from a mixture of small and big molecules". Based on this observation, we made a hypothesis that an $\mathrm{H}$-filter could be used for determination of adulterated melamine in dairy products, as it might be used for isolation of melamine (small molecules) from the mixture. 
Table 3. Concentrations and amounts of Tartrazine calculated

\begin{tabular}{|c|c|c|c|c|c|}
\hline & & Absorbance & Conc. $(\mathrm{mg} / \mathrm{ml})$ & Volume of Soln. (ml) & Tartrazine (mg) \\
\hline \multirow{6}{*}{ Extracted } & Filter $1(20 \mathrm{~mm})$ & 0.202 & 0.0445 & 0.05 & 0.0022 \\
\hline & Filter $2(25 \mathrm{~mm})$ & 0.196 & 0.0432 & 0.05 & 0.0022 \\
\hline & Filter $3(20 \mathrm{~mm})$ & 0.204 & 0.0449 & 0.05 & 0.0022 \\
\hline & Filter $4(25 \mathrm{~mm})$ & 0.189 & 0.0416 & 0.05 & 0.0021 \\
\hline & Filter $5(20 \mathrm{~mm})$ & 0.202 & 0.0445 & 0.05 & 0.0022 \\
\hline & Filter $6(25 \mathrm{~mm})$ & 0.198 & 0.0436 & 0.05 & 0.0022 \\
\hline Loaded & & & 0.5000 & 0.20 & 0.1000 \\
\hline
\end{tabular}

Table 4. Extraction percentage of tartrazine

\begin{tabular}{|l|l|}
\hline & Extraction percentage from loaded sample (\%) \\
\hline Filter $1(20 \mathrm{~mm})$ & 2.224 \\
\hline Filter $2(25 \mathrm{~mm})$ & 2.158 \\
\hline Filter $3(20 \mathrm{~mm})$ & 2.246 \\
\hline Filter $4(25 \mathrm{~mm})$ & 2.080 \\
\hline Filter $5(20 \mathrm{~mm})$ & 2.224 \\
\hline Filter $6(25 \mathrm{~mm})$ & 2.180 \\
\hline
\end{tabular}

Table 5. Summary of the Nanodrop testing results

\begin{tabular}{|c|c|c|c|c|}
\hline$\#$ & Sample ID & $\mathbf{1 ~ ( n m )}$ & $\mathbf{1 ~ ( A b s )}$ & 2 (nm) \\
\hline $\mathbf{1}$ & 1000MELAMINE & 230 & 1.908 & \\
\hline $\mathbf{2}$ & 25BSA & 230 & 0.433 & 280 \\
\hline $\mathbf{3}$ & 25BSA1Me & 230 & 1.064 & 280 \\
\hline $\mathbf{4}$ & 25BSA1Me-sample1 & 210 & 1.627 & 280 \\
\hline $\mathbf{5}$ & 25BSA1Me-sample2 & 230 & 0.699 & 280 \\
\hline $\mathbf{6}$ & 25BSA1Me-sample3 & 230 & 0.706 & 280 \\
\hline
\end{tabular}

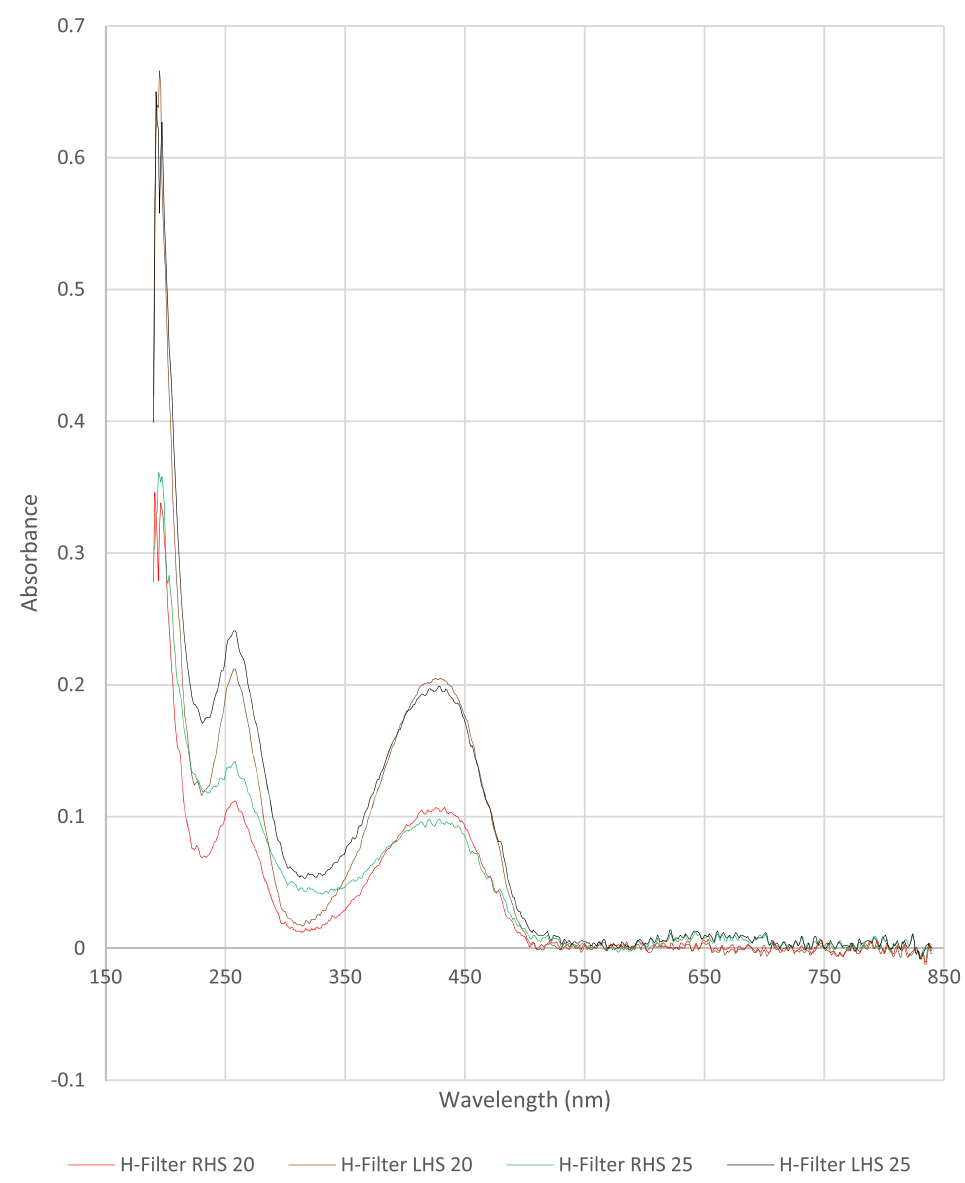

Figure 3. An example of UV Absorbance plots for H-filter tests, obtained using a Nanodrop Spectrophotometer 


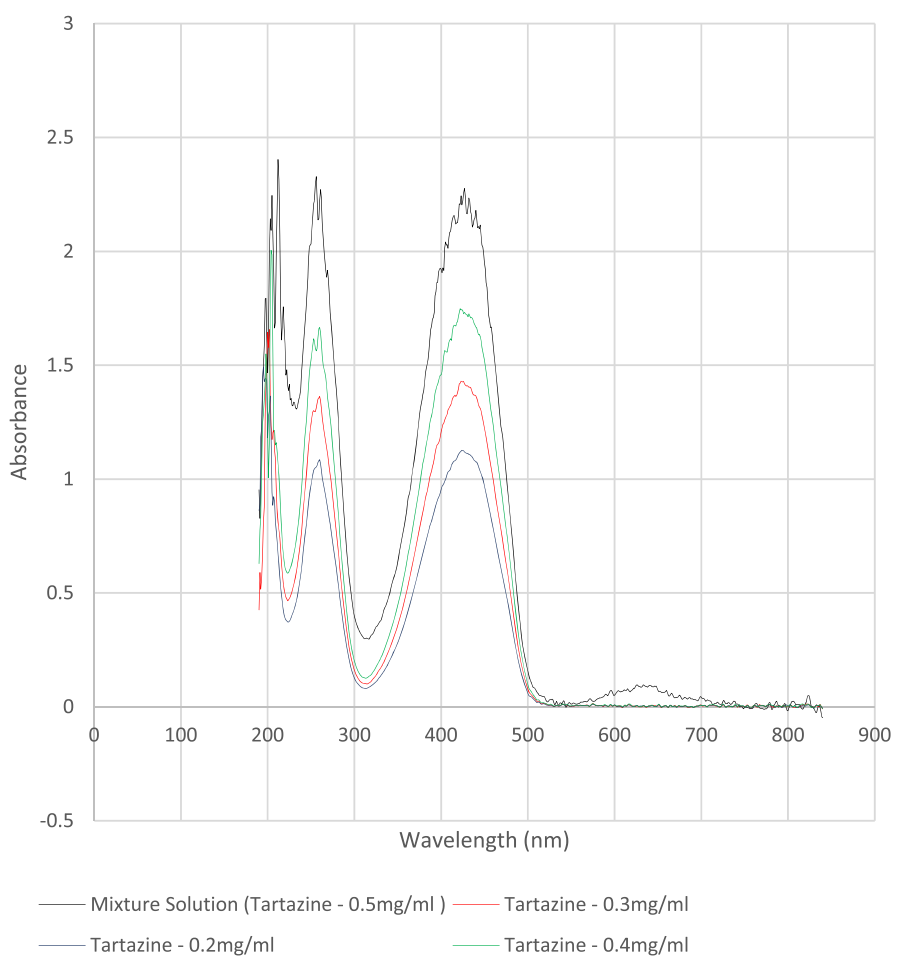

Figure 4. UV Absorbance plots for known concentrations of Tartrazine

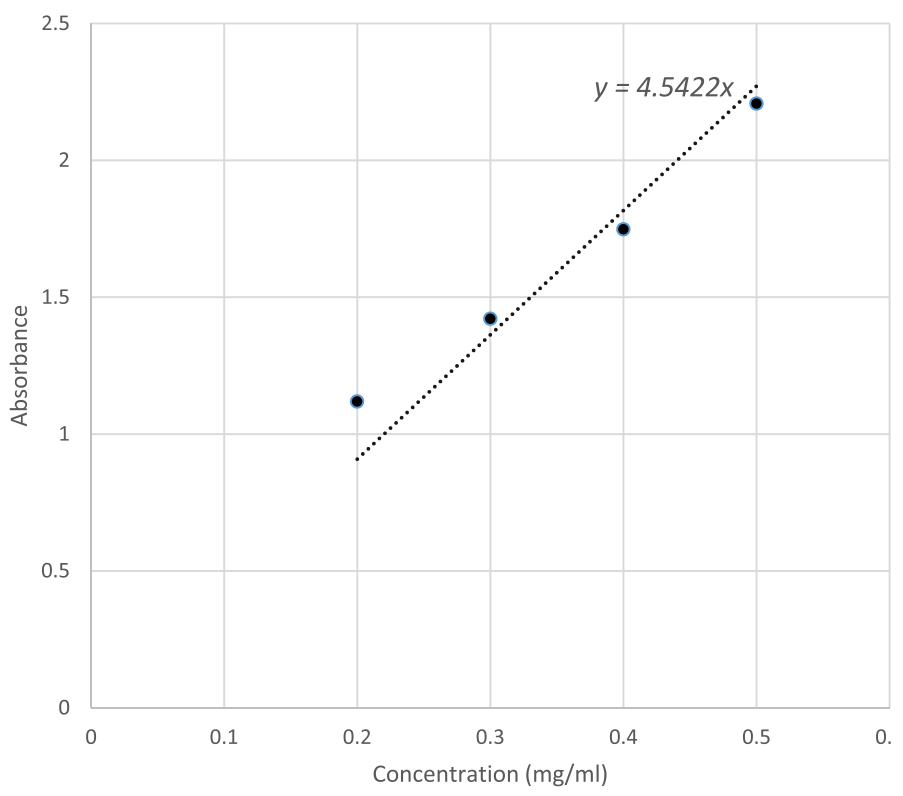

Figure 5. Line of best fit for tartrazine standard curve

\section{Results of the separation of milk-melamine}

Figures 6-13 show the curves of the Nanodrop testing. Table 5 summarizes the test results. '1000MELAMINE' means the concentration of melamine in $1 \mathrm{XPBS}$ is $1 \mathrm{mg} / \mathrm{ml}$. '25BSA' means the concentration of BSA in 1 XPBS is $25 \mathrm{mg} / \mathrm{ml}$. '25BSA1Me' means the mixture of $1 \mathrm{mg} / \mathrm{ml} \mathrm{melamine}$ and $25 \mathrm{mg} / \mathrm{mL}$ BSA with the ratio of 1:1.

The first peak is at wavelength $220-230 \mathrm{~nm}$, which represents melamine whose absorbance increases from sample 1 to sample 4 . This means that melamine was separated and pre-concentrated at the left end of the chip (samples 3 and 4). The second peak represents BSA at wavelength $280 \mathrm{~nm}$; the absorbance decreases form sample 1 to sample 3. This means BSA was depleted from the mixture and moved to the rightest most end of the chip. This is because melamine has higher density, compared to the large molecule BSA, and thus it would travel slower than the BSA molecules. During the separation process, melamine molecules flow slower and accumulate more at the left end of the chip. On the other hand, BSA has the lower density and would travel faster; hence during separation it would flow towards the right end of the chip.

Sample 1 is the rightest most of the chip and sample 4 is the left end of the chip. There is a shift in the first peak. However, after increasing 


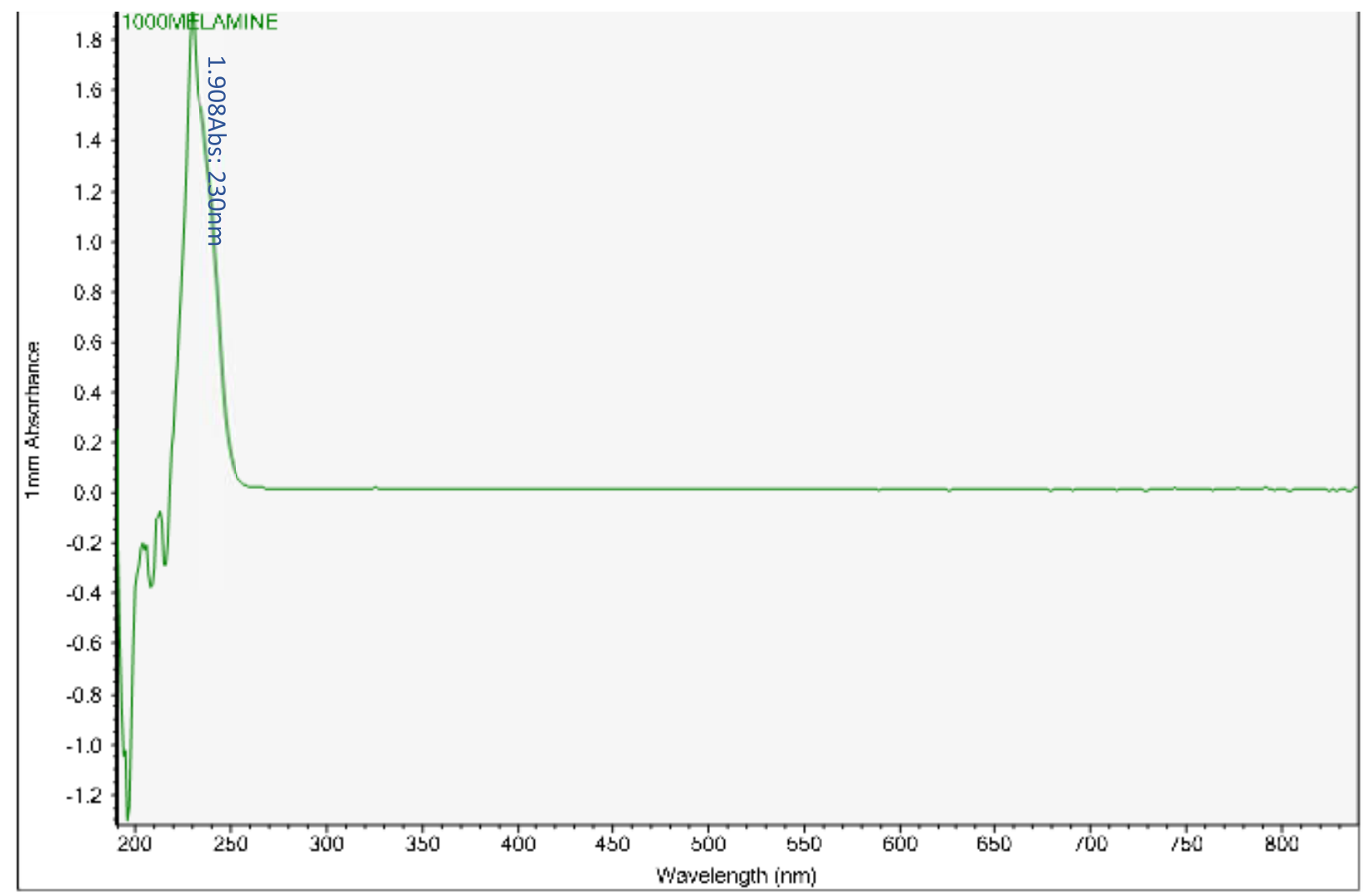

Figure 6. UV-vis absorbance of $1 \mathrm{mg} / \mathrm{mL}$ melamine solution

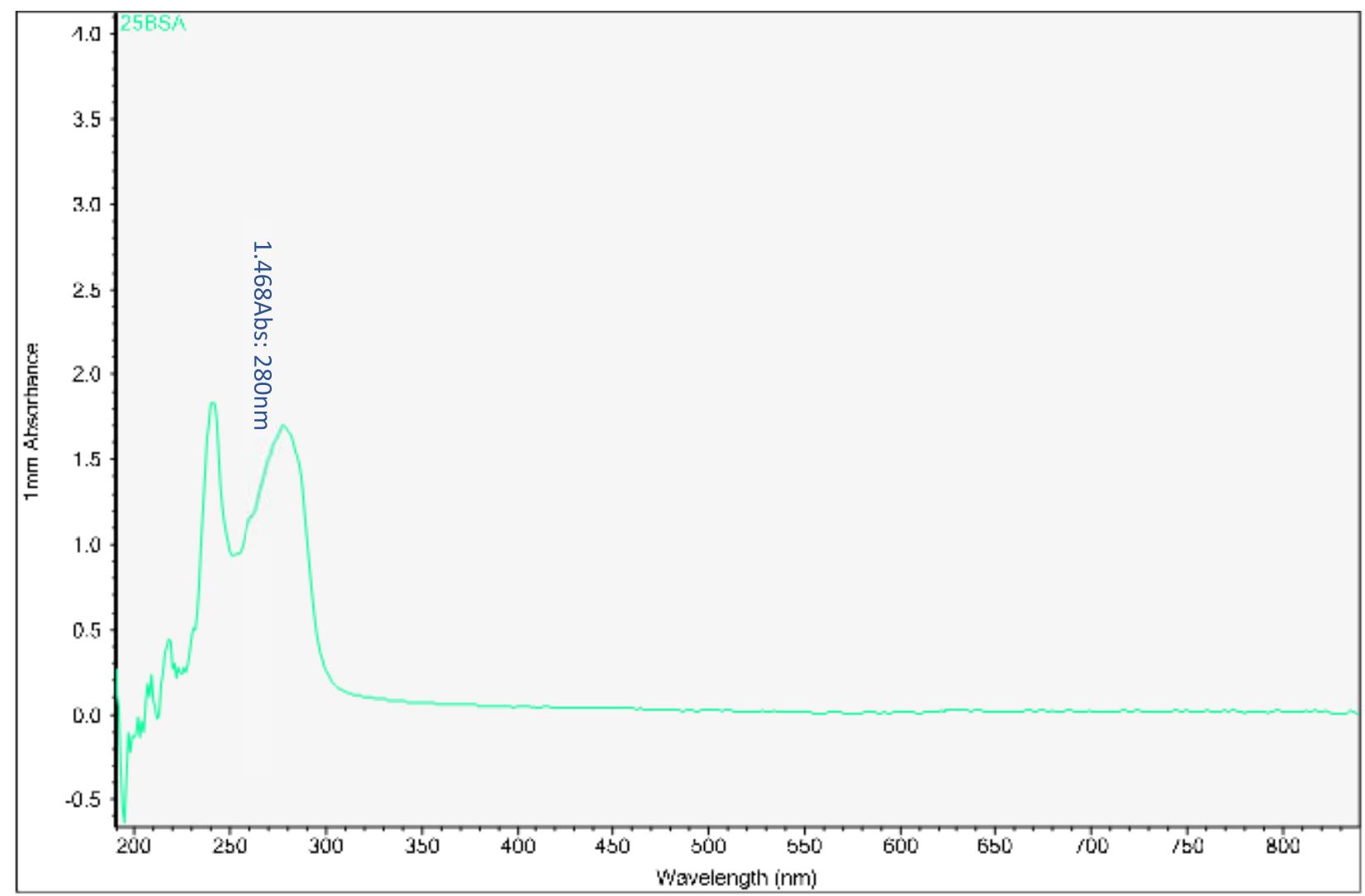

Figure 7. UV-vis absorbance of $25 \mathrm{mg} / \mathrm{mL}$ BSA in $1 \mathrm{xPBS}$ 


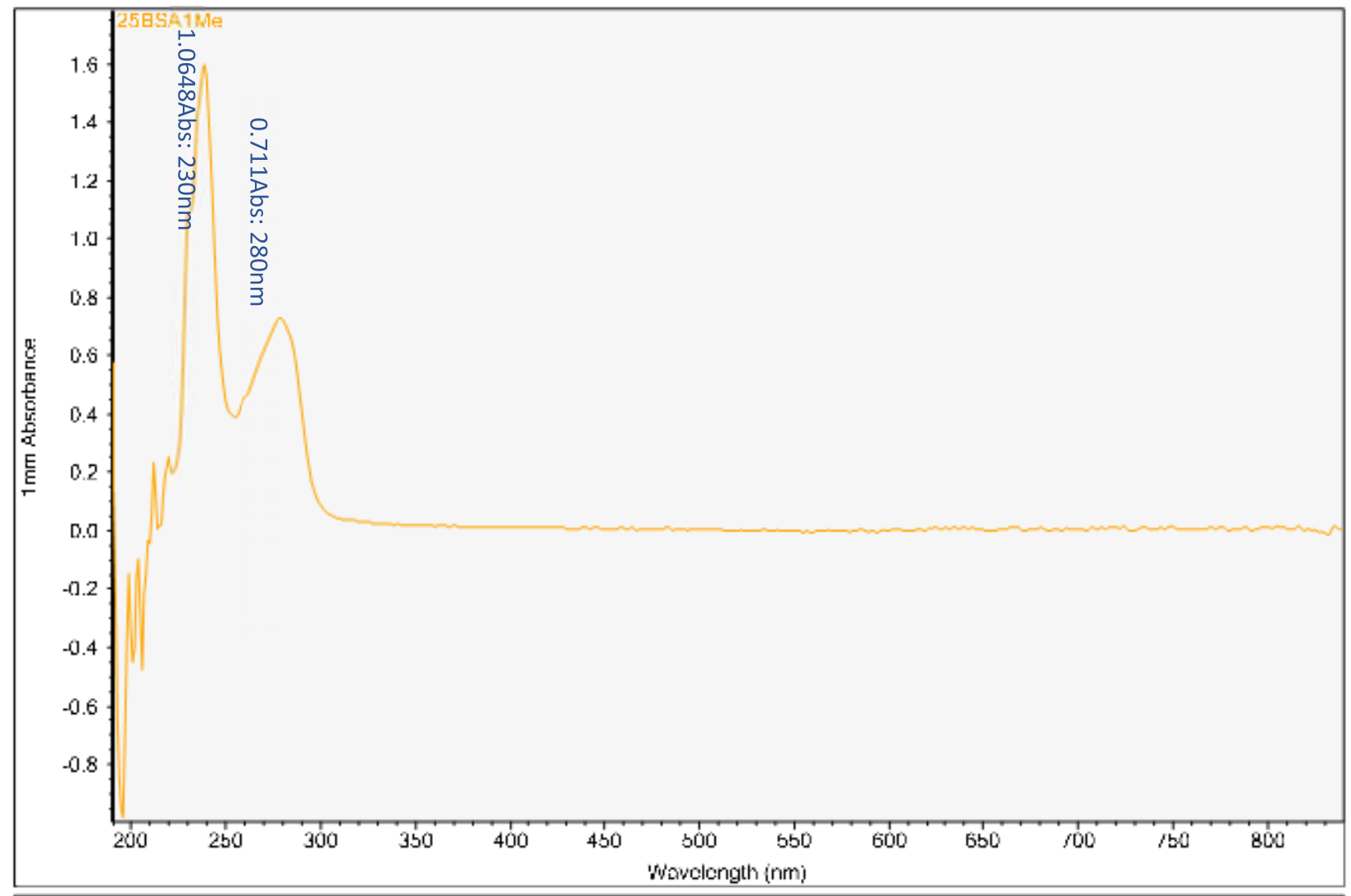

Figure 8. UV-vis absorbance of mixture of $1 \mathrm{mg} / \mathrm{mL}$ melamine and $25 \mathrm{mg} / \mathrm{mL}$ BSA in $1 x P B S$

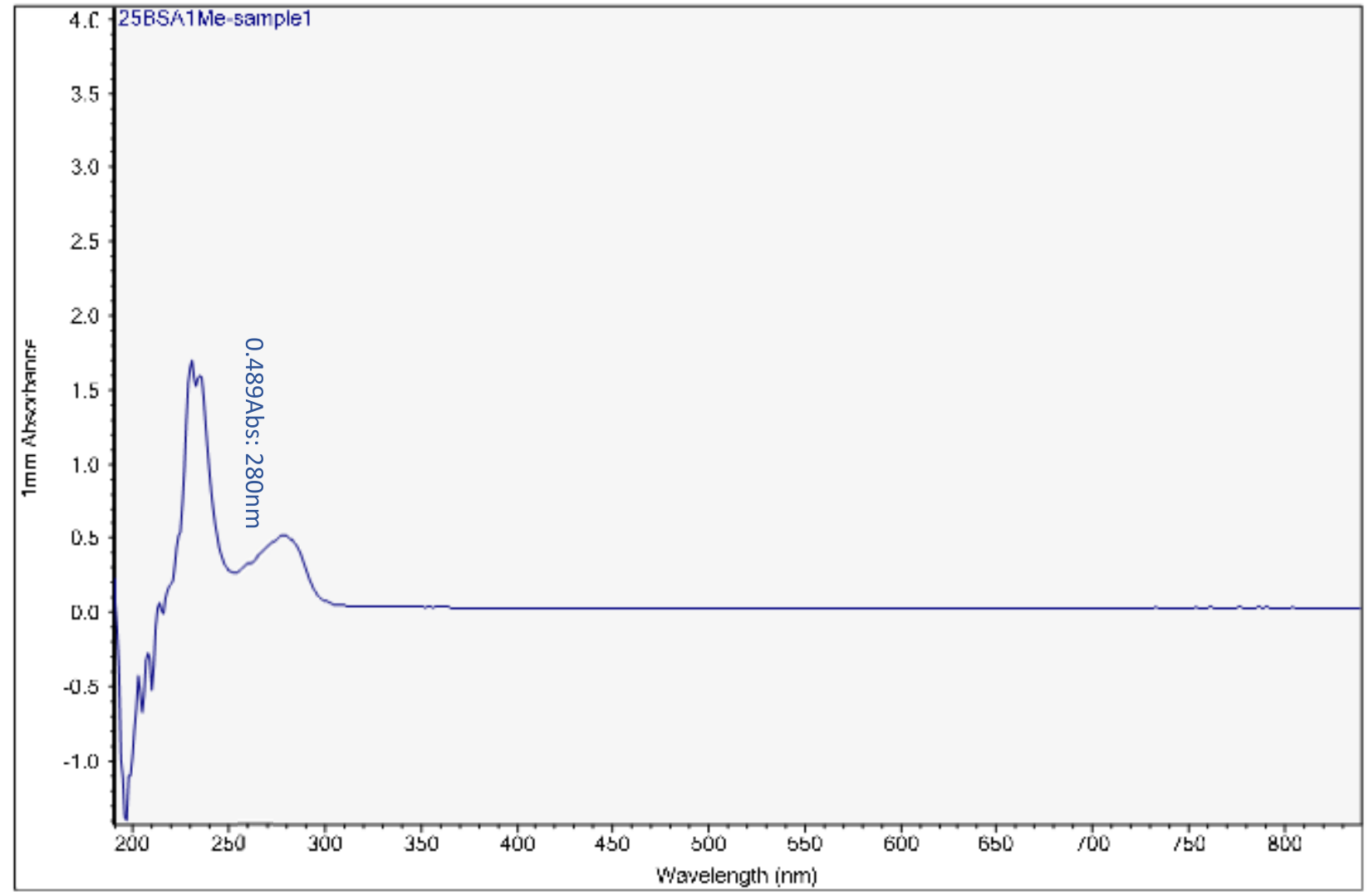

Figure 9. UV-vis absorbance of soaked solution obtained from sample 1 of the $\mathrm{H}$ filter chip 


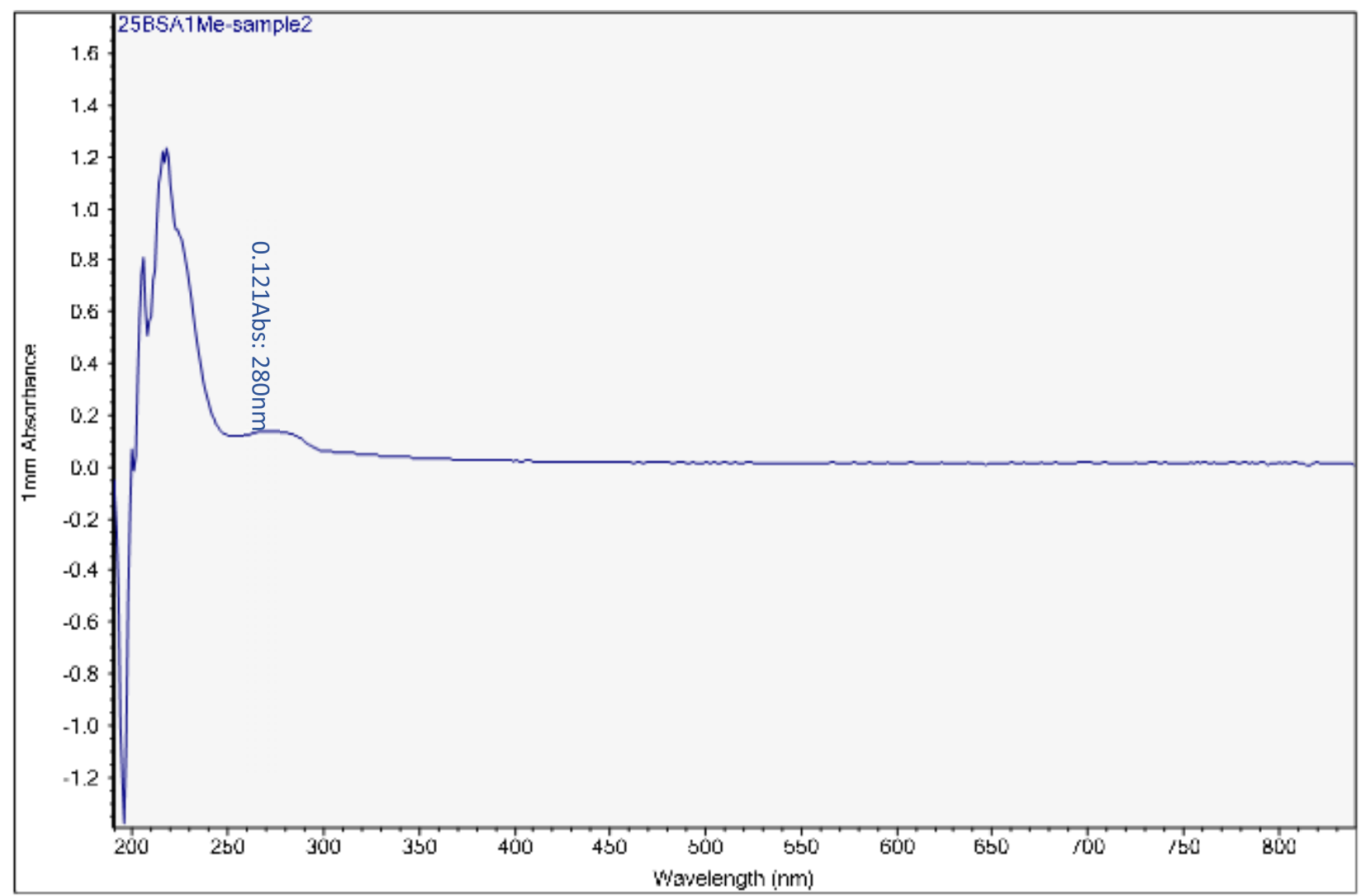

Figure 10. UV-vis absorbance of soaked solution obtained from sample 2 of the $\mathrm{H}$ filter chip

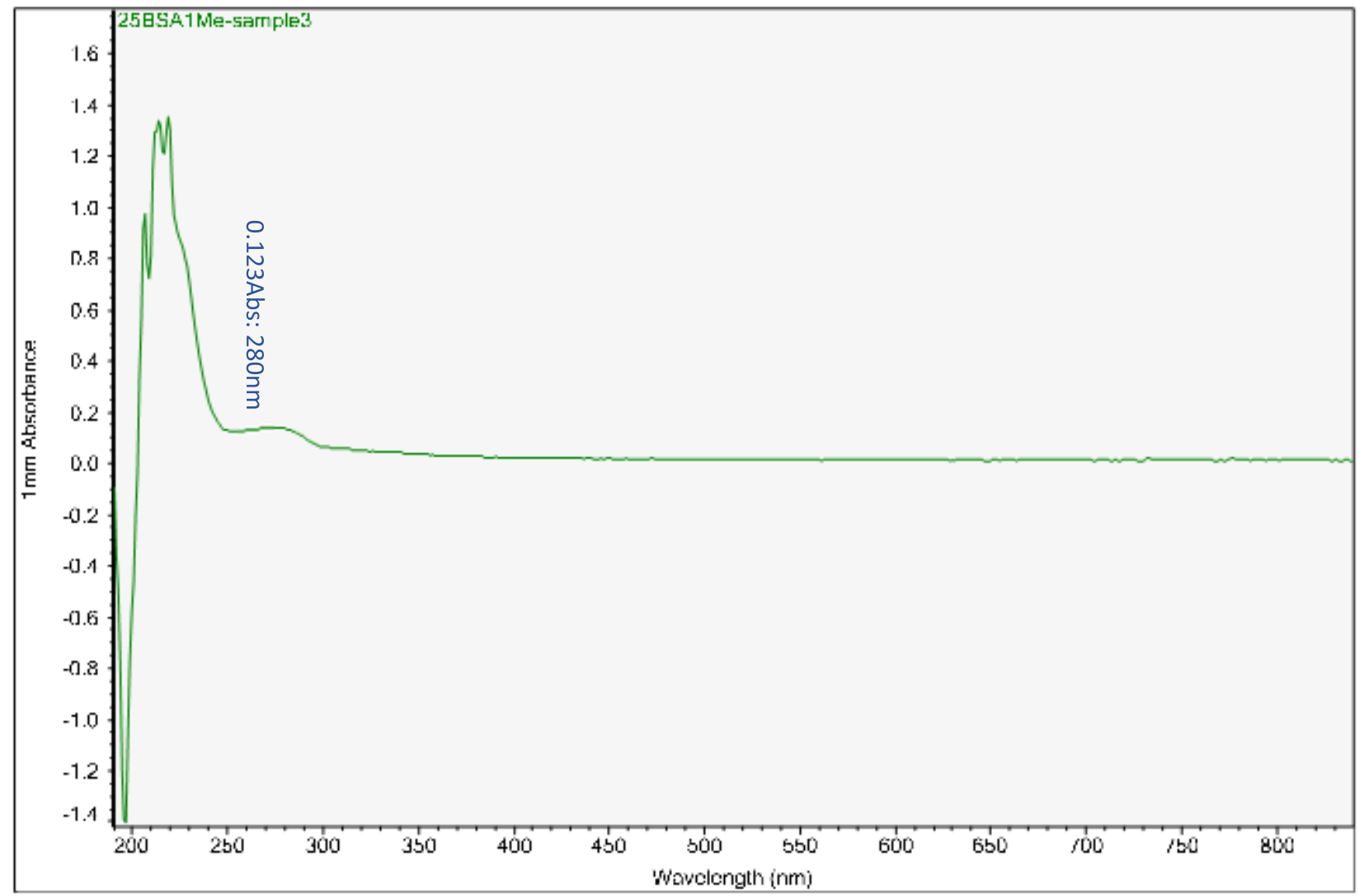

Figure 11. UV-vis absorbance of soaked solution obtained from sample 3 of the $\mathrm{H}$ filter chip 


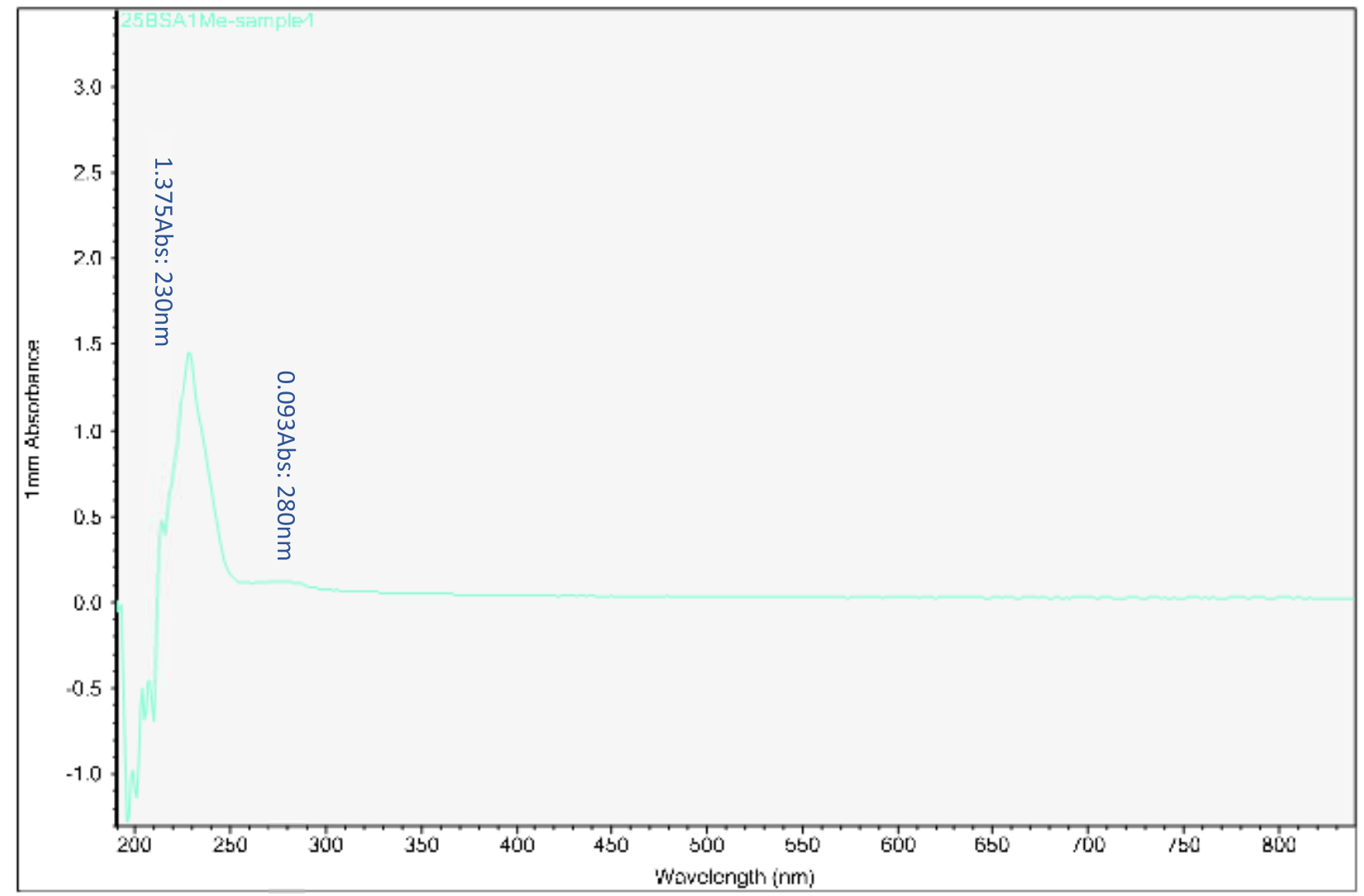

Figure 12. UV-vis absorbance of soaked solution obtained from sample 4 of the H filter chip

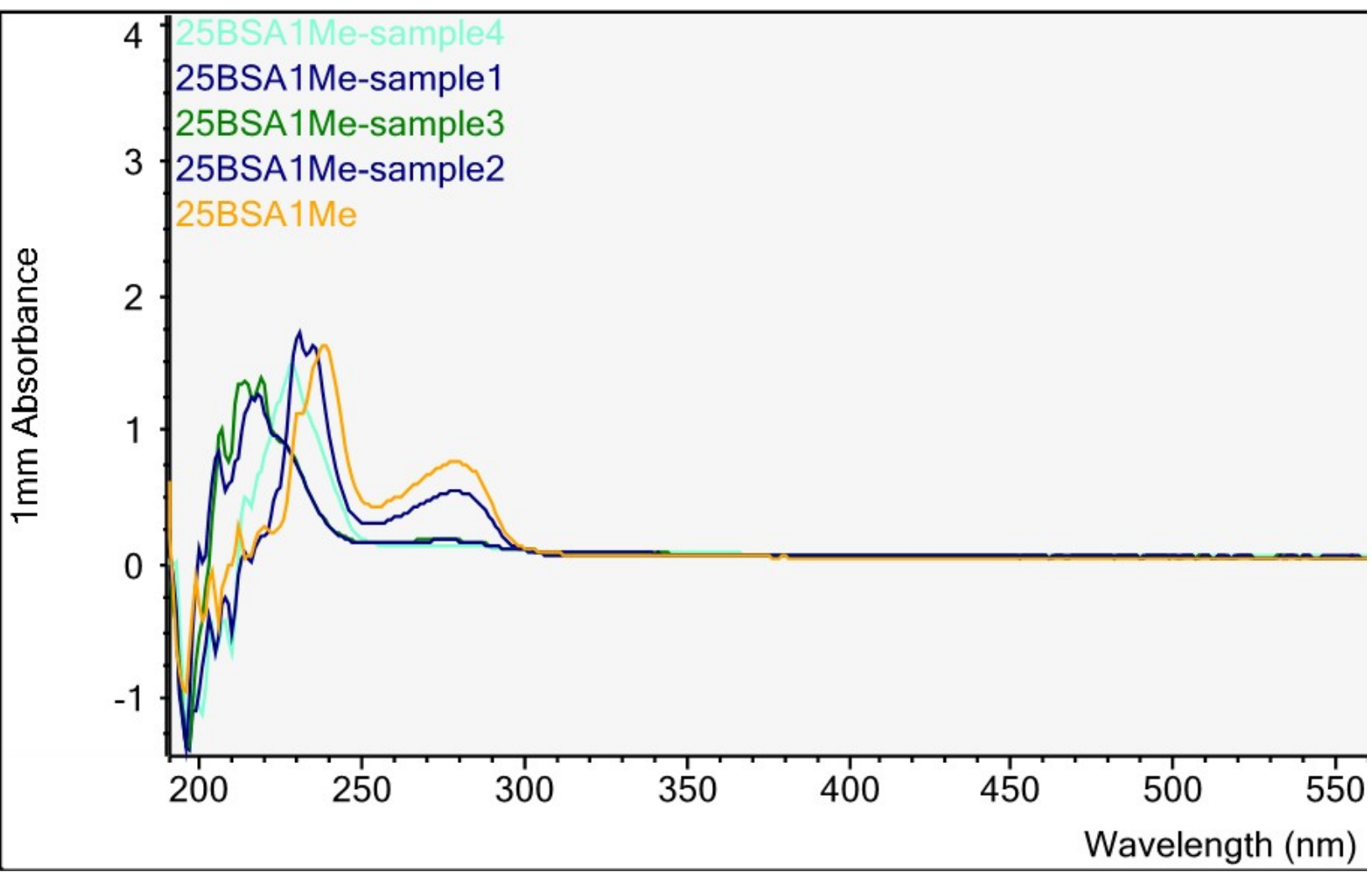

Figure 13. UV-vis absorbance of pure melamine $(1 \mathrm{mg} / \mathrm{mL}), 25 \mathrm{mg} / \mathrm{mL}$ BSA, mixture of melamine and BSA, soaked solutions obtained from samples $1-4$ of the $\mathrm{H}$ filter chip 
the concentration of BSA solution, typical absorbance peak at $280 \mathrm{~nm}$ for BSA solution can be observed clearly. The absorbance peaks are 0.489 to 0.093 Abs for sample 1 to sample 4 .

What we care most is the second peak at $280 \mathrm{~nm}$, which is the typical peak of BSA. Based on the results, BSA concentration has decreased significantly from sample 1 to sample 4 , which indicates a very good removal of BSA from the target analyte (melamine).

It should be noted that the Nanodrop testing is not a must to be conducted as soon as possible after separation. But the chip must be cut in to 4 samples as fast as possible once the chip is observed to be fully wet. Otherwise, the flow of fluid from the 2 wells will still continue and the absorbent end of the chip will start to have fluid accumulation and cause mixture to become homogenous again. For sample 4, there was a sudden surge of BSA absorbance as this might happen due to the prolong soaking of the chip where mixture became homogenous again after separation.

\section{Conclusion}

For the purpose of the food safety, the paper-based microfluidic devices for melamine detection were tested. UV-vis absorbance value curves of the mixture solution and extraction solution showed the extraction of the small molecule (melamine) by the developed paper microfluidic device. The $\mathrm{H}$-filter can be used for determination of adulterated melamine in dairy products, as it can be used for isolation of melamine (small molecules) from the mixture. Test results revealed a very good depletion of BSA from the target analyte (melamine).

\section{References}

1. Astolfi ML, Marconi E, Protano C, Canepari S (2020) Comparative elemental analysis of dairy milk and plant-based milk alternatives. Food Control 116: 107327.

2. Guo JQ, Wu CH, Zhang JM, Chang XL, Zhang YB, et al. (2020) Associations of melamine and cyanuric acid exposure with markers of kidney function in adults: Results from NHANES 2003-2004. Environ Int 141: 105815. [Crossref]

3. Newton GL, Utley PR (1978) Melamine as a dietary nitrogen-source for ruminants. Journal of Animal Science 47: 1338-1344.

4. Thompson M, Owen L, Wilkinson K, Wood R, Damant A (2002) A comparison of the Kjeldahl and Dumas methods for the determination of protein in foods, using data from a proficiency testing scheme. Analyst 127: 1666-1668. [Crossref]

5. Serdiuk T, Skryshevsky VA, Phaner-Goutorbe M, Souteyrand E (2010) Monitoring of melamine contamination in fat watery milk by the photoluminescence analysis. Talanta 82: $1543-1547$.

6. Ehling S, Tefera S, Ho IP (2007) High-performance liquid chromatographic method for the simultaneous detection of the adulteration of cereal flours with melamine and related triazine by-products ammeline, ammelide, and cyanuric acid. Food Addit Contam 24: 1319-1325. [Crossref]

7. PerkinElmer (2015) Milk Adulteration with Melamine - Screening, Testing and Real Time Detection. Food Fraud.

8. WHO (2019) Toxicological and Health Aspects of Melamine and Cyanuric Acid. World Health Organisation.

9. Kumar N, Seth R, Kumar H (2014) Colorimetric detection of melamine in milk by citrate- stabilized gold nanoparticles. Analytical Biochemistry 456: 43-49.

10. Sushma U, Srivastava AK, Krishnan MH (2019) Melamine Detection in Food Matrices Employing Chicken Antibody (IgY): A Comparison between Colorimetric and Chemiluminescent Methods. Current Analytical Chemistry 15: 668-677.

11. Giovannozzi AM, Rolle F, Sega M, Abete MC, Marchis D, et al. (2014) Rapid and sensitive detection of melamine in milk with gold nanoparticles by Surface Enhanced Raman Scattering. Food Chemistry 159: 250-256.

12. Nascimento CF, Rocha DL, Rocha FRP (2015) A fast and environmental friendly analytical procedure for determination of melamine in milk exploiting fluorescence quenching. Food Chemistry 169: 314-319.
13. Guo ZN, Cheng ZY, Li R, Chen L, Lv HM, et al. (2014) One-step detection of melamine in milk by hollow gold chip based on surface-enhanced Raman scattering. Talanta 122: 80-84.

14. Batista AD, Nascimento CF, Melchert WR, Rocha FRP (2014) Expanding the separation capability of sequential injection chromatography: Determination of melamine in milk exploiting micellar medium and on-line sample preparation. Microchemical Journal 117: 106-110.

15. Hu YX, Feng SL, Gao F, Li-Chan, E. Grant, et al. (2015) Detection of melamine in milk using molecularly imprinted polymers-surface enhanced Raman spectroscopy. Food Chemistry 176: 123-129.

16. Zhai C, Qiang W, Sheng J, Lei JP, Ju HX (2010) Pretreatment-free fast ultraviolet detection of melamine in milk products with a disposable microfluidic device. $J$ Chromatogr A 1217: 785-789. [Crossref]

17. Goodman W (2019) Solid Phase Extraction and GC/MS Analysis of Melamine Adulteration in Dairy Products. PerkinElmer.

18. Filazi A, Sireli UT, Ekici H, Can HY, Karagoz A (2012) Determination of melamine in milk and dairy products by high performance liquid chromatograph. Journal of Dairy Science 95: 602-608.

19. Hu Y, Feng S, Gao F, Li-Chan ECY, Grant E, et al. (2015) Detection of melamine in milk using molecularly imprinted polymers-surface enhanced Raman spectroscopy. Food Chemistry 176: 123-129.

20. Jiao XZ, Meng YY, Wang KK, Huang W, Li N, et al. (2019) Rapid Detection of Adulterants in Whey Protein Supplement by Raman Spectroscopy Combined with Multivariate Analysis. Molecules 24: 1889. [Crossref]

21. Lampinen J, Perälä A, Harinen RR (2019) High Sensitivity ELISA Assays for the Detection of Melamine Residuals in Milk.

22. Ping H, Zhang M, Li H, Li S, Chen Q, et al. (2012) Visual detection of melamine in raw milk by label-free silver nanoparticles. Food Control 23: 191-197.

23. Lachenmeier DW, Humpfer E, Fang F, Schuetz B, Dvortsak P, et al. (2009) NMRSpectroscopy for Nontargeted Screening and Simultaneous Quantification of HealthRelevant Compounds in Foods: The Example of Melamine. J Agric Food Chem 57: 7194-7199. [Crossref]

24. Tang HW, Ng KM, Chui SSY, Che CM, Lam CW, et al. (2009) Analysis of Melamine Cyanurate in Urine Using Matrix-Assisted Laser Desorption/Ionization Mass Spectrometry. Anal Chem 81: 3676- 3682. [Crossref]

25. Chen W, Jiang Y, Ji B, Zhu C, Liu L, et al. (2009) Automated and ultrasensitive detection of methyl-3-quinoxaline-2- carboxylic acid by using gold nanoparticles probes SIA-rt-PCR. Biosensors \& Bioelectronics 24: 2858-2863.

26. Mazivila SJ, Pascoa R, Castro RC, Ribeiro DSM, Santos JLM (2020) Detection of melamine and sucrose as adulterants in milk powder using near-infrared spectroscopy with DD-SIMCA as one-class classifier and MCR-ALS as a means to provide pure profiles of milk and of both adulterants with forensic evidence: A short communication. Talanta 216: 120937. [Crossref]

27. Vinciguerra LL, Marcelo MCA, Motta TMC, Meneghini LZ, Bergold AM, et al. (2019) Chemometric tools and ftir-atr spectroscopy applied in milk adulterated with cheese whey. Quimica Nova 42: 249-254.

28. Conceicao DG, Goncalves BRF, da Hora FF, Faleiro AS, Santos LS, et al. (2019) Use of FTIR-ATR Spectroscopy Combined with Multivariate Analysis as a Screening Too to Identify Adulterants in Raw Milk. Journal of the Brazilian Chemical Society 30: 780-785.

29. Balan B, Dhaulaniya AS, Jamwal R, Yadav A, Kelly S, et al. (2020) Rapid detection and quantification of sucrose adulteration in cow milk using Attenuated tota reflectance-Fourier transform infrared spectroscopy coupled with multivariate analysis. Spectrochimica Acta Part a-Molecular and Biomolecular Spectroscopy 240: 118628.

30. Gonzalez RRR, Cobuccio L, Delatour T (2019) Reconstitution followed by nontargeted mid-infrared analysis as a workable and cost-effective solution to overcome the blending duality in milk powder adulteration detection. Food Chemistry 295: 42-50.

31. Bergana MM, Adams KM, Harnly J, Moore JC, et al. (2019) Non-targeted detection of milk powder adulteration by H-1 NMR spectroscopy and conformity index analysis. Journal of Food Composition and Analysis 78: 49-58.

32. Valentine CJ, Takagishi K, Umezu S, Daly R, De Volder M (2020) Paper-Based Electrochemical Sensors Using Paper as a Scaffold to Create Porous Carbon Nanotube Electrodes. ACS Applied Materials \& Interfaces 12: 30680-30685. 
33. Zhong ZW, Wang ZP, Huang GXD (2012) Investigation of wax and paper materials for the fabrication of paper-based microfluidic devices. Microsys Technol 18: 649- 659.

34. Moniz T, Bassett CR, Almeida M, Kolev SD, Rangel M, et al. (2020) Use of an ether-derived 3-hydroxy-4-pyridinone chelator as a new chromogenic reagent in the development of a microfluidic paper-based analytical device for Fe(III) determination in natural waters. Talanta 214: 120887.

35. Trofimchuk E, Hu YX, Nilghaz A, Hua MZ, Sun SLN, et al. (2020) Development of paper-based microfluidic device for the determination of nitrite in meat, Food Chemistry 316: 126396. [Crossref]

36. Osborn JL, Lutz B, Fu E, Kauffman P, Stevens DY, et al. (2010) Microfluidics without pumps: reinventing the T-sensor and H-filter in paper networks. Lab Chip 10: 26592665. [Crossref]
37. Niyonambaza SD, Boisselier E, Boukadoum M, Miled A (2018) Microfluidic H-filter Cell Modeling for Robust Purification of Gold Nanoparticles, in 2018 16th Ieee International New Circuits and Systems Conference pp: 370-373.

38. Urteaga R, Elizalde E, Berli CLA (2018) Transverse solute dispersion in microfluidic paper- based analytical devices (mu PADs). Analyst 143: 2259-2266.

39. Matellan C, Hernandez AED (2018) Cost-effective rapid prototyping and assembly of poly (methyl methacrylate) microfluidic devices. Scientific Reports.

40. Yager P, Brody J (2010) Microfluidics without pumps: reinventing the T-sensor and $\mathrm{H}$-filter in paper networks. Lab on Chip.

41. Zhong ZW, Wu RG, Wang ZP, Tan HL (2015) An investigation of paper based microfluidic devices for size based separation and extraction applications. Journal of Chromatography B 1000: 41-48.

Copyright: $\odot 2020 \mathrm{Wu}$ RG. This is an open-access article distributed under the terms of the Creative Commons Attribution License, which permits unrestricted use, distribution, and reproduction in any medium, provided the original author and source are credited. 